\title{
Determination of Transformation Temperatures of Advanced High-Strength Steels and Their Use in Designing Q\&P Process Routes
}

\author{
Dagmar Bublíková ${ }^{1}$, Hana Jirková ${ }^{1}$, Mária Behúlová ${ }^{2}$, Josef Krajčovič² \\ ${ }^{1}$ University of West Bohemia, RTI-Regional Technological Institute, Univerzitní 22, CZ - 30614 Pilsen, Czech Republic, \\ E-mail: h.jirkova@email.cz, dagmar.bublikova@seznam.cz \\ ${ }^{2}$ Slovak University of Technology in Bratislava, Fakulty of Materials Science and Technology in Trnava, J. Bottu 25, \\ SK-91724 Trnava, Slovakia, E-mail: josef.krajcovic1@stuba.sk, maria.behulova@stuba.sk
}

Determining transformation temperatures of novel steels is an important step towards finding parameters for their heat treatment. In advanced high-strength steels for Q\&P processing (Quenching and Partitioning), the crucial processing characteristics are the temperatures of the start and end of austenitization and the $M_{s}$ temperature. Q\&P processing is characterized by quenching from a full-austenitization temperature to below the $M_{s}$, and subsequent holding at the partitioning temperature. This leads to martensitic microstructures with retained austenite between martensite needles and to ultimate strengths above $2000 \mathrm{MPa}$ and elongation levels up to 10\%. Several AHS steels containing $0.4 \% \mathrm{C}$ were manufactured and cast for this experiment. Their main alloying additions were manganese, silicon, chromium, molybdenum and nickel. Their transformation temperatures were first calculated using the JMatPro software. The values were validated by dilatometry measurements. Based on these results, a Q\&P process route was designed and put to test. The resulting microstructures were documented using optical and scanning electron microscopy. Strengths of more than $2300 \mathrm{MPa}$ and up to $11 \%$ elongation levels were obtained.

Keywords: dilatometry, JMatPro, Q\&P process, retained austenite, AHSS, X-ray diffraction

\section{Introduction}

If desired mechanical properties are to be achieved in modern AHS steels, not only must these steels have the right chemistry but their heat treatment must be chosen correctly. Modern treatment methods which lead to the required properties include the $\mathrm{Q} \& \mathrm{P}$ process. It allows strengths of more than $2000 \mathrm{MPa}$ to be achieved, together with elongation levels of about $10 \%[1,2]$. It is characterized by rapid cooling from the austenite region to a temperature between $\mathrm{M}_{\mathrm{s}}$ and $\mathrm{M}_{\mathrm{f}}$. The initial microstructure (Fig. 1) thus transforms to a martensitic microstructure with some retained austenite (Fig. 2). During the subsequent holding at a partitioning temperature, carbon migrates from super-saturated martensite to austenite and stabilises the latter [3, 4]. Retained austenite greatly improves ductility. However, its volume fraction in the final microstructure must be $10-15 \%$ in order to provide sufficient impact on mechanical properties.

As Q\&P processing is a complicated technology for which a vast number of parameters must be optimised, its development cannot be undertaken under production conditions. Material-technological modelling in a thermomechanical simulator is therefore very useful (Fig. 3) [5-7]. The simulator offers high-frequency resistive heating of samples and rapid heating and cooling. Temperature is measured with a thermocouple which is welded onto the sample.

Important information for designing a Q\&P process route includes transformation temperatures of the workpiece material. They can be determined using various calculations based on phenomenological models, with the aid of software tools, such as JMatPro, or with the use of a dilatometer. Using the JMatPro software, the phase transformation temperatures $\mathrm{Ac}_{1}, \mathrm{Ac}_{3}, \mathrm{M}_{\mathrm{s}}$ and $\mathrm{M}_{\mathrm{f}}$ can be calculated from chemical composition. The optional parameters in this procedure are austenitizing temperature, which the software sets at $50^{\circ} \mathrm{C}$ above the $\mathrm{Ac}_{3}$, and grain size [8]. Based on CCT and TTT diagrams calculated using JMatPro, one can determine the cooling rate for producing the desired microstructure.

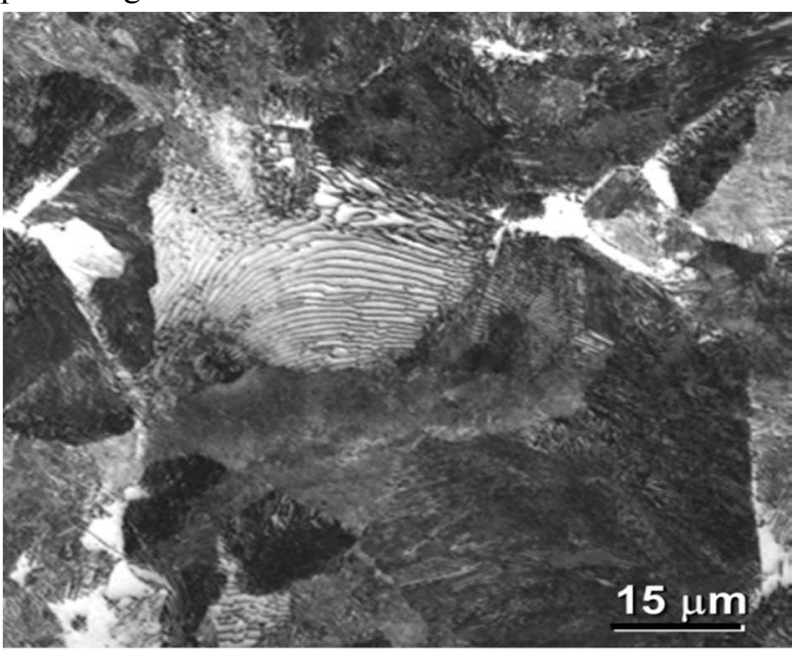

Fig. 1 Initial ferritic-pearlitic structure before $Q \& P$ processing

Using dilatometry, length changes caused by physical or chemical processes in the material of interest can be studied. The length of the specimen during a defined thermal process is monitored with a sensor [9]. From the resulting dilatometric curves one can derive the desired phase transformation temperatures. These include, for instance, the $A_{c 1}$ and $A_{c 3}$, temperatures of the start and end of austenitization during heating. During cooling, the temperature of austenite decomposition to ferrite, $\mathrm{A}_{\mathrm{r} 3}$, the pearlite transformation start and finish temperatures $\mathrm{P}_{\mathrm{s}}$ 
and $\mathrm{P}_{\mathrm{f}}$, the bainite transformation start and finish temperatures $\mathrm{B}_{\mathrm{s}}, \mathrm{B}_{\mathrm{f}}$, and the martensite start and finish temperatures $\mathrm{M}_{\mathrm{s}}$ and $\mathrm{M}_{\mathrm{f}}$ can be identified, depending on the cooling rate and chemical composition of the material. A phase transformation region begins where the dilatometric curve deviates from a straight line. Another phase starts to form at a point of inflection on the curve [10].

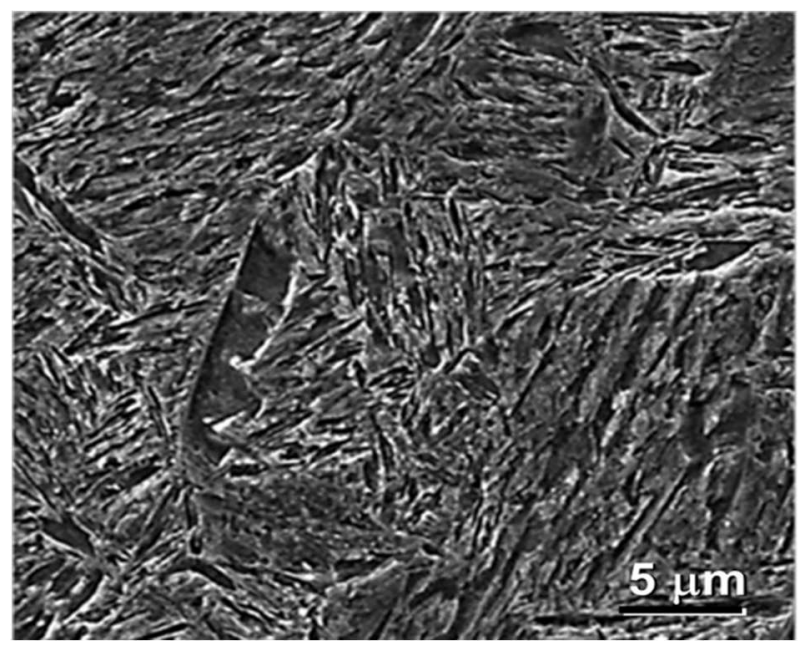

Fig. 2 Martensitic-bainitic structure with retained austenite after $Q \& P$ processing

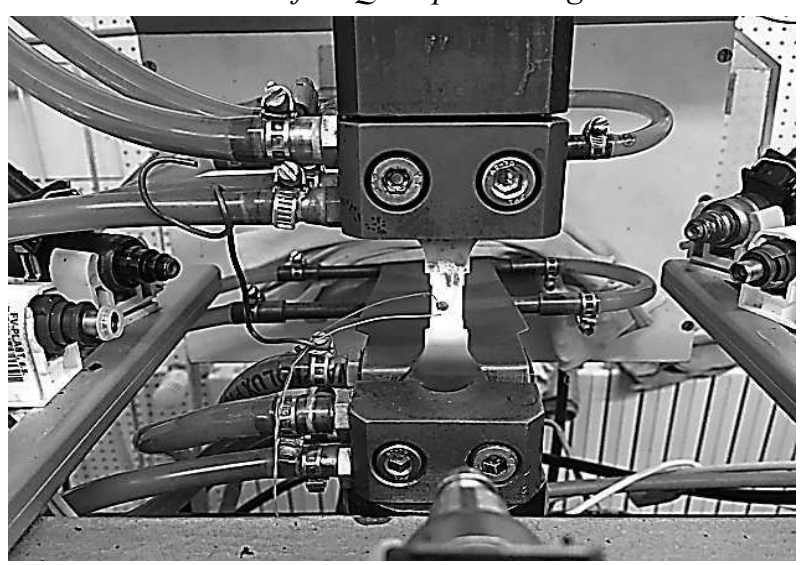

\section{Experiment}

Q\&P processing requires that quenching is halted between the $\mathrm{M}_{\mathrm{s}}$ and $\mathrm{M}_{\mathrm{f}}$. Considering this requirement, four experimental steels were created whose chemistries depressed their $\mathrm{M}_{\mathrm{s}}$ temperatures (Tab.1). The main alloying additions in the steels whose carbon content was around $0.4 \%$ were manganese and silicon. Manganese lowers the $\mathrm{M}_{\mathrm{s}}$ and $\mathrm{M}_{\mathrm{f}}$ temperatures significantly and shifts the ferritic and pearlitic transformations towards lower cooling rates in transformation diagrams. Silicon was added to prevent carbide formation to ensure martensite becomes super-saturated with carbon. The purpose of chromium was to increase hardenability and provide solid solution strengthening. Nickel was employed to improve the stability of austenite and provide better hardenability. The initial material contained martensite and a small proportion of pearlite and showed a strength of approx. $1030 \mathrm{MPa}$ and an elongation of $17 \%$.

For Q\&P processing, the workpiece is heated to a fullaustenite region and then quenched between the martensite start and finish temperatures. Therefore, the heat treater needs to know the Ac1 and Ac3 temperatures, as well as the temperatures which characterise the austenite-tomartensite decomposition and the critical cooling rate.

First, the transformation temperatures of all the experimental steels were calculated from chemical composition using JMatPro 9.0 [8]. The $\mathrm{Ac}_{1}$ and $\mathrm{Ac}_{3}$ transformation temperatures as well as the appropriate cooling rate for obtaining the desired hardening microstructure with the right mechanical properties were derived from continuous-cooling transformation diagrams (CCT diagrams) (Fig. 4 - Fig. 7).

These calculated temperatures were compared with phase transformations obtained from dilatometric plots of heating (Fig. 8 - Fig. 14). The dilatometer was a Netzsch DIL $402 \mathrm{C}$ instrument. The dimensions of the square cross-section specimens were $2 \times 2 \times 20 \mathrm{~mm}$. The specimens were heated to $1100^{\circ} \mathrm{C}$ at $30^{\circ} \mathrm{C} /$ minute.

Fig. 3 Thermomechanical simulator

Tab. 1 Chemical compositions of experimental AHS steels [wt. \%]

\begin{tabular}{|l|c|c|c|c|c|c|c|c|c|c|c|c|c|}
\multicolumn{1}{c|}{} & $\mathbf{C}$ & $\mathbf{M n}$ & $\mathbf{S i}$ & $\mathbf{P}$ & $\mathbf{S}$ & $\mathbf{C u}$ & $\mathbf{C r}$ & $\mathbf{N i}$ & $\mathbf{A l}$ & $\mathbf{M o}$ & $\mathbf{N b}$ & $\mathbf{M}$ & $\mathbf{M}_{\mathbf{f}}$ \\
\hline AHSS1 & 0.430 & 2.5 & 2.03 & 0.006 & 0.003 & 0.07 & 1.33 & 0.07 & 0.008 & 0.03 & 0.03 & 218 & 88 \\
\hline AHSS2 & 0.428 & 2.48 & 2.03 & 0.005 & 0.003 & 0.07 & 1.46 & 0.08 & 0.004 & 0.16 & 0.03 & 214 & 83 \\
\hline AHSS3 & 0.419 & 2.45 & 2.09 & 0.005 & 0.002 & 0.06 & 1.34 & 0.56 & 0.005 & 0.04 & 0.03 & 209 & 78 \\
\hline AHSS4 & 0.426 & 2.46 & 1.99 & 0.005 & 0.002 & 0.06 & 1.33 & 0.56 & 0.005 & 0.16 & 0.03 & 204 & 73 \\
\hline
\end{tabular}

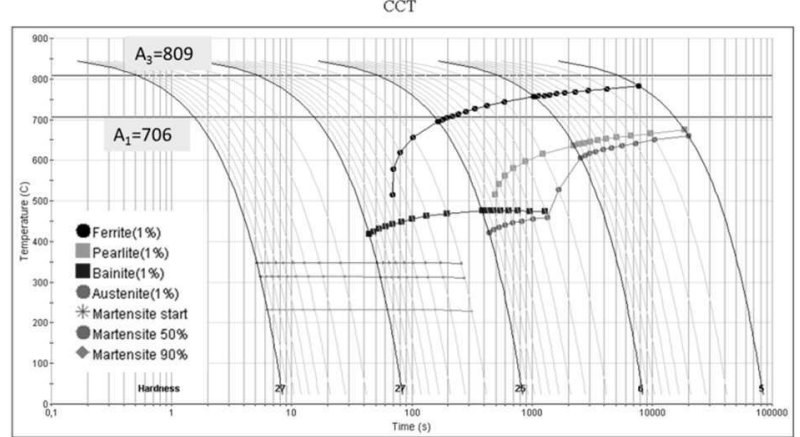

Fig. 4 AHSS1 - CCT diagram - Ni 0.07\%, Mo 0.03\%

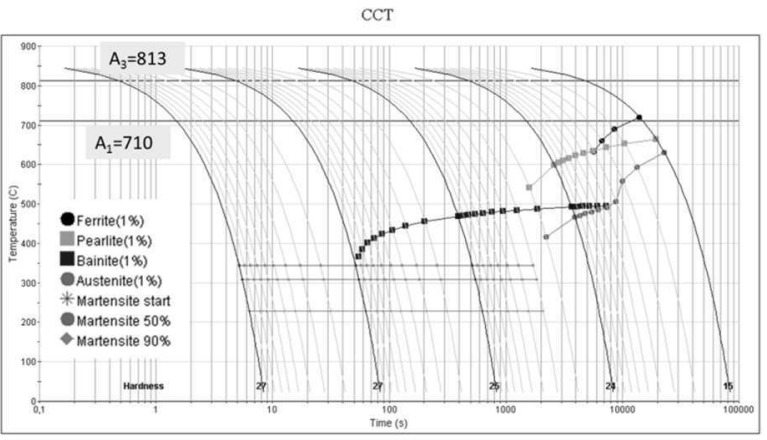

Fig. 5 AHSS2 - CCT diagram - Ni 0.08\%, Mo 0.16\% 
CCT

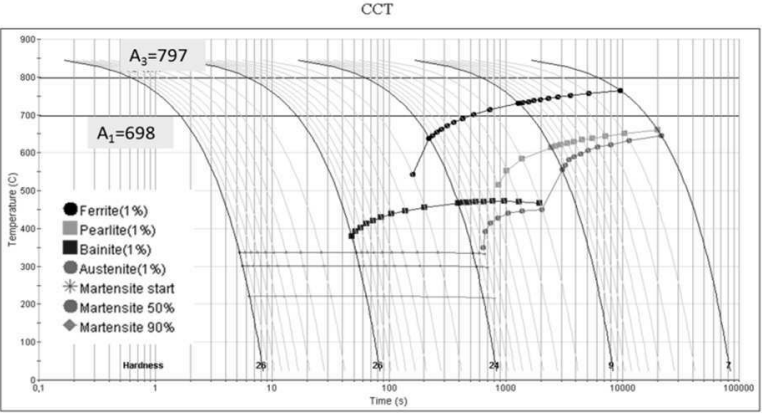

Fig. 6 AHSS3 - CCT diagram - Ni 0.56\%, Mo 0.03\%

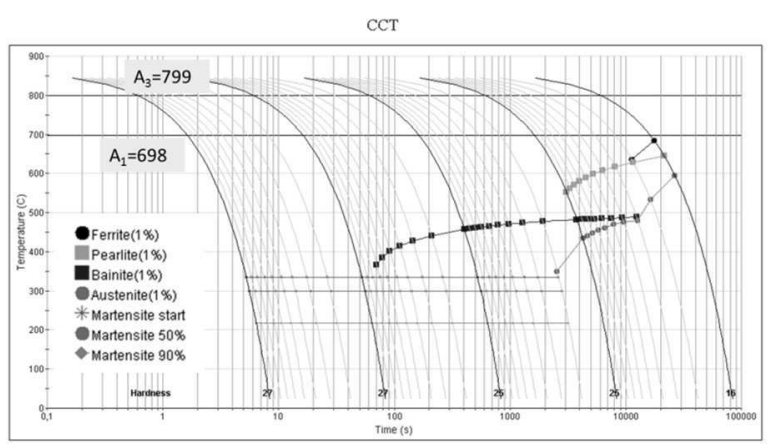

Fig. 7 AHSS4 - CCT diagram Ni 0.56\%, Mo 0.16\%

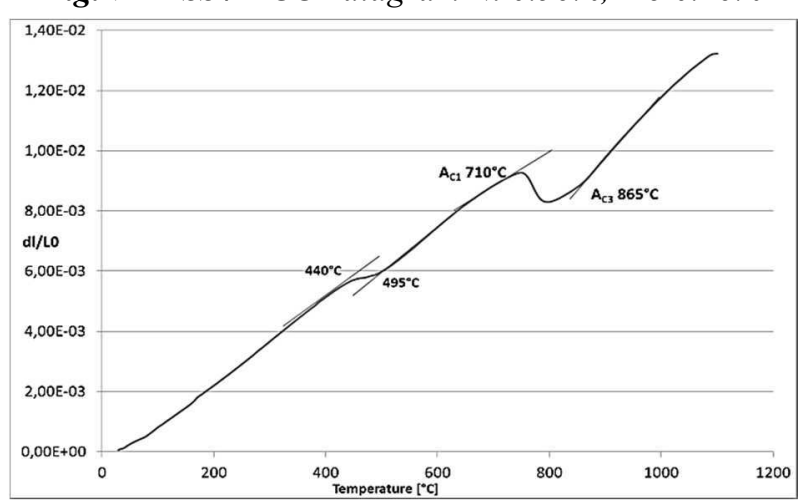

Fig. 8 AHSS1 - dilatometric plot of heating at $30^{\circ} \mathrm{C} / \mathrm{min}$

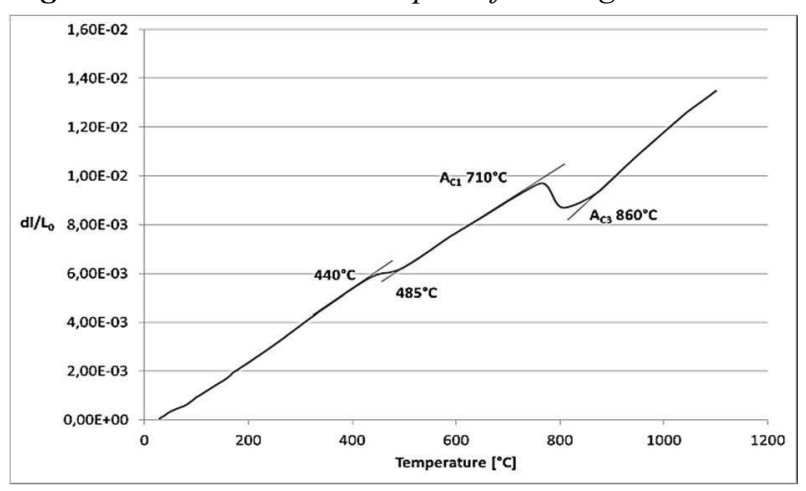

Fig. 9 AHSS 2 - dilatometric plot of heating at $30^{\circ} \mathrm{C} / \mathrm{min}$

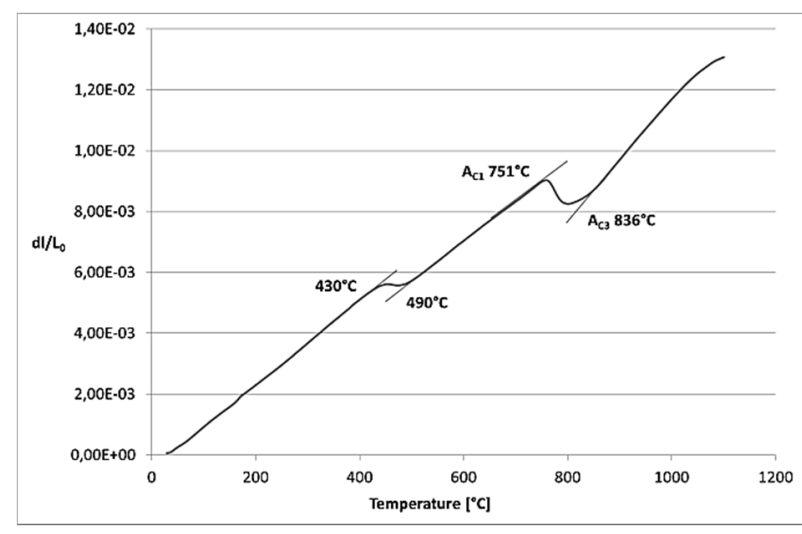

Fig. 10 AHSS3 - dilatometric plot of heating at $30^{\circ} \mathrm{C} / \mathrm{min}$

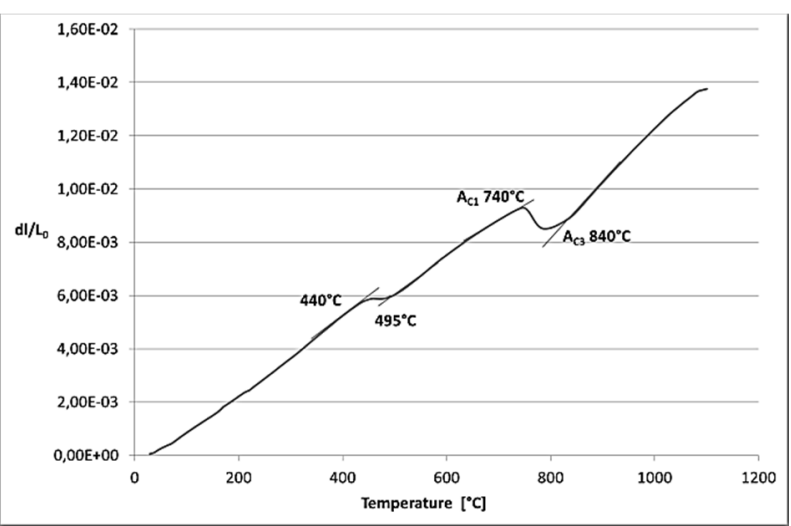

Fig. 11 AHSS4 - dilatometric plot of heating at $30^{\circ} \mathrm{C} / \mathrm{min}$

\section{Q\&P process}

After comparing the transformation temperatures calculated using JMatPro and dilatometric data, a Q\&P process sequence was designed (Tab. 2). The austenitizing temperature (TA) was set at $850^{\circ} \mathrm{C}$ and the quenching temperature (QT) was chosen as $150^{\circ} \mathrm{C}$, which is between the $\mathrm{M}_{\mathrm{s}}$ and $\mathrm{M}_{\mathrm{f}}$. An important parameter is the partitioning temperature (PT). During partitioning, carbon migrates from super-saturated martensite to austenite to stabilise it. Cooling rates were chosen on the basis of CCT diagrams (Fig. 4 - Fig. 7). The goal was to get clear of the pearlite nose. Specimens treated in this way were then used for metallographic examination and mechanical testing: measurement of HV10 hardness and miniature tensile testing. The specimen cross-section was $2 \times 1.2 \mathrm{~mm}$ and the gauge length was $5 \mathrm{~mm}$. The amount of retained austenite was measured using X-ray diffraction (Tab. 2).

Tab. 2 Heat treatment routes and results of mechanical testing

\begin{tabular}{|c|c|c|c|c|c|c|c|c|}
\hline $\begin{array}{c}\text { Route num- } \\
\text { ber/steel type }\end{array}$ & $\mathbf{T}_{\mathbf{A}}\left[{ }^{\circ} \mathbf{C}\right] / \mathbf{t}_{\mathbf{A}}[\mathbf{s}]$ & $\mathbf{C o o l i n g} \mathbf{r a t e}\left[{ }^{\circ} \mathbf{C} / \mathbf{s}\right]$ & $\mathbf{Q T}\left[{ }^{\circ} \mathbf{C}\right]$ & $\begin{array}{c}\text { PT }\left[{ }^{\circ} \mathbf{C} / \mathbf{s}\right] \\
/ \mathbf{t} \text { TT }[\mathbf{s}]\end{array}$ & $\mathbf{H V 1 0}[-]$ & $\begin{array}{c}\mathbf{R}_{\mathbf{m}} \\
(\mathbf{U T S})\end{array}$ & $\begin{array}{c}\mathbf{A} 5 \mathbf{m m} \\
{[\mathbf{M P}]}\end{array}$ & $\begin{array}{c}\mathbf{R A} \\
{[\mathbf{\%}]}\end{array}$ \\
\hline AHSS1 & $850 / 100$ & 1 & 150 & $200 / 600$ & 671 & 2289 & 9 & 10 \\
\hline AHSS2 & $850 / 100$ & 1 & 150 & $200 / 600$ & 636 & 2302 & 10 & 10 \\
\hline AHSS3 & $850 / 100$ & 1 & 150 & $200 / 600$ & 679 & 2308 & 10 & 12 \\
\hline AHSS4 & $850 / 100$ & 1 & 150 & $200 / 600$ & 690 & 2346 & 8 & 12 \\
\hline
\end{tabular}




\section{Discussion of results}

According to the calculation using JMatPro, the temperatures of the start and end of austenite formation, $\mathrm{A}_{\mathrm{c} 1}$ $\mathrm{A}_{\mathrm{c} 3}$, in the heats denoted as AHSS1 and AHSS2, i.e. the steels with higher Mo levels, were near identical: approximately $710^{\circ} \mathrm{C}$ and $810^{\circ} \mathrm{C}$, respectively (Fig. 4, Fig. 5). For both heats, the $\mathrm{A}_{\mathrm{c} 1}$ temperature determined with the use of dilatometer was almost exactly the same as the value calculated using JMatPro: about $710^{\circ} \mathrm{C}$. For both steels, the $\mathrm{A}_{\mathrm{c} 3}$ determined with dilatometry was higher than that calculated with JMatPro: around $860{ }^{\circ} \mathrm{C}$ (Fig. 8, Fig. 9). In AHSS3 and AHSS4 steels, in which the nickel content was $0.56 \%$, i.e. higher than in AHSS1 and AHSS 2, the $A_{c 1}$ and $A_{c 3}$ calculated using JMatPro were about $690^{\circ} \mathrm{C}$ and $790^{\circ} \mathrm{C}$, respectively (Fig. 6, Fig. 7). The measured Ac1 values were higher than the calculated ones: $751^{\circ} \mathrm{C}$ in AHSS3 and $740^{\circ} \mathrm{C}$ in AHSS4 (Fig. 10, Fig. 11). The same holds for the Ac3: $836^{\circ} \mathrm{C}$ in AHSS3 and $840^{\circ} \mathrm{C}$ in AHSS4. Based on these results, the same soaking temperatures and times were chosen for all the experimental steels: $850^{\circ} \mathrm{C}$ and $100 \mathrm{~s}$, respectively.

Dilatometric curves also indicate the temperature of the start and end of decomposition of martensite to an equilibrium mixture of ferrite and cementite. This temperature was almost identical for all heats: in the range of $440-490^{\circ} \mathrm{C}$ (Fig. $6-$ Fig. 11). The $\mathrm{M}_{\mathrm{s}}$ and $\mathrm{M}_{\mathrm{f}}$ temperatures were determined by no other means than the JMatPro program because dilatometric measurements were only conducted during heating. The lowest temperatures of the start and end of martensite transformation, $204^{\circ} \mathrm{C}$ and $73^{\circ} \mathrm{C}$, were found for the AHSS4 steel, which had higher levels of nickel and molybdenum (Tab. 1).

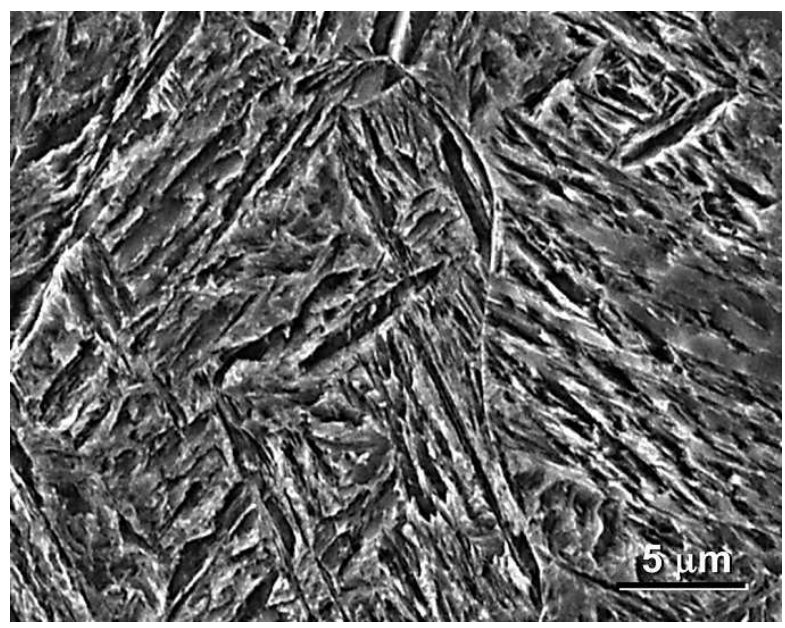

Fig. 12 AHSS1 - Martensitic microstructure with bainite and $10 \%$ of retained austenite - scanning electron micrograph

The Q\&P process sequence which comprised soaking at $850^{\circ} \mathrm{C}$ and quenching to $150^{\circ} \mathrm{C}(\mathrm{QT})$ and which involved a partitioning temperature $(\mathrm{PT})$ of $200^{\circ} \mathrm{C}$ produced a martensitic structure with bainite and $10-12 \%$ retained austenite in all steels (Fig. 12 - Fig. 15). Ultimate strength levels were in the range of 2302-2346 MPa and the elongation interval was $8-10 \%$ (Tab. 2). The highest ultimate strength, $2344 \mathrm{MPa}$, was found in AHSS4, the steel which contained higher nickel and molybdenum levels. Both elements affect the strength of the solid solution. In this case, elongation was the lowest: $8 \%$. The largest amounts of retained austenite (12 vol. \%) were found by X-ray diffraction measurement in AHSS3 and AHSS4. This was probably owing to the higher nickel content which affects the stabilisation of retained austenite in martensitic matrix. It was obvious from the X-ray diffraction analysis that the microstructures were fine-grained.

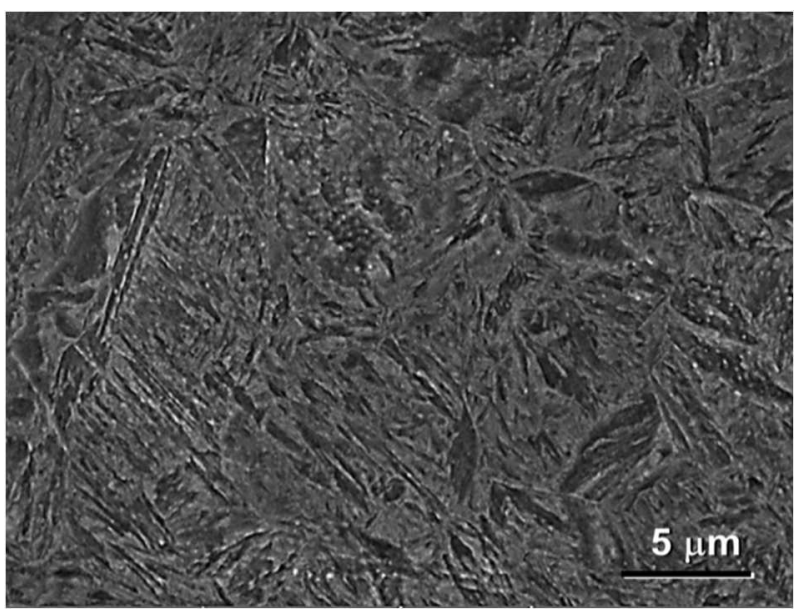

Fig. 13 AHSS2 - Martensitic microstructure with bainite and $10 \%$ of retained austenite - scanning electron micrograph

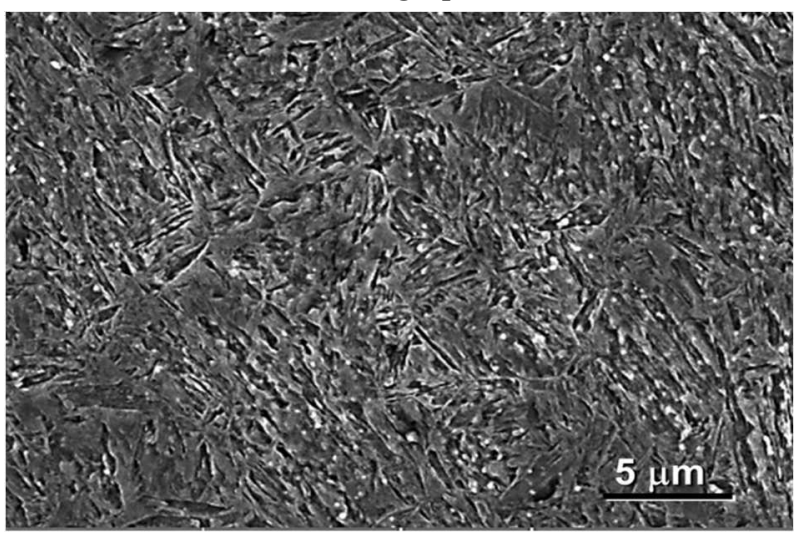

Fig. 14 AHSS3 - Fine martensitic microstructure with bainite and $12 \%$ of retained austenite - scanning electron micrograph

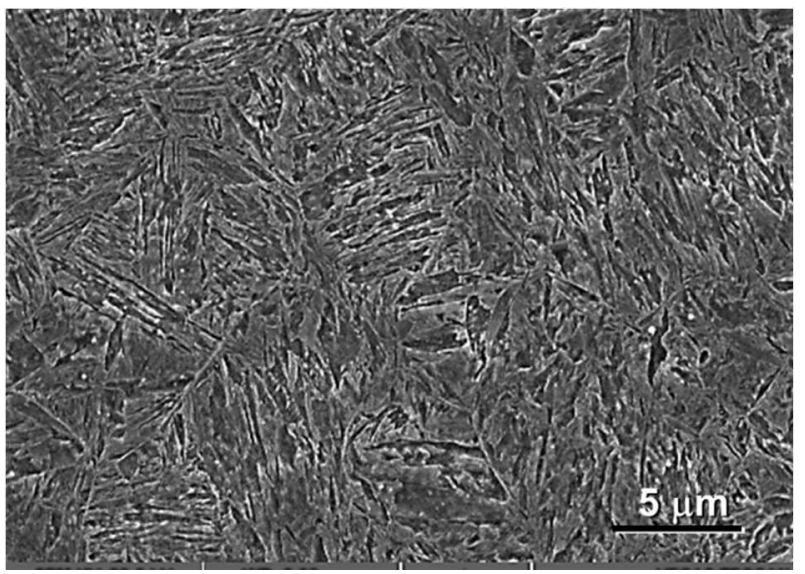

Fig. 15 AHSS4 - Fine martensitic microstructure with bainite and $12 \%$ of retained austenite - scanning electron micrograph 


\section{Conclusion}

An innovative heat treatment method, the Q\&P process, was tested on newly-designed experimental AHS steels. This method combines quenching and partitioning operations. As a result, it leads to high strengths combined with good elongation. In the first step, the phase transformation temperatures for the experimental steels were determined for designing the actual sequence. Two methods were used: a calculation using the JMatPro software and dilatometric measurement. As a result, it was also possible to determine the appropriate soaking temperature of $850^{\circ} \mathrm{C}$ and the right quenching and partitioning temperatures of $150^{\circ} \mathrm{C}$ and $200^{\circ} \mathrm{C}$, respectively.

Martensitic structures with bainite and approx. 10\% retained austenite were obtained in all the experimental heats. Ultimate strength levels were in the range of 2302$2346 \mathrm{MPa}$ and the elongation interval was $8-10 \%$. The highest ultimate strength was found in the AHSS4 steel, which had higher molybdenum and nickel levels: $2346 \mathrm{MPa}$. Elongation reached 8\%. The largest amounts of retained austenite ( 12 vol. \%) were found by X-ray diffraction measurement in the AHSS3 and AHSS4 steels. The reason was the higher level of nickel, an element which affects stabilisation of retained austenite in martensitic matrix.

\section{Acknowledgement}

This paper includes results achieved within the project SGS-2016-060 Research of Modern AHS Steels and Innovative Processing for their Manufacturing. The project is subsidised from specific resources of the state budget for research and development.

\section{References}

[1] MAŠEK, B., JIRKOVÁ, H., HAUSEROVÁ, D., KUČEROVÁ, L., KLAUBEROVÁ D. The Effect of $\mathrm{Mn}$ and Si on the Properties of Advanced High Strength Steels Processed by Quenching and Partitioning. Materials Science Forum, (2010), Vol. 654-656, pp. 94-97.

[2] EDMONDSA, D.V.; HEA, K.; RIZZO, F.C.; DE COOMANC, B.C.; MATLOCK, D.K.; SPEER,
J.G.: Quenching and partitioning martensite - A novel steel heat treatment, Materials Science and Engineering A, (2006), Vol. 438-440, pp. 25-34, https://doi.org/10.1016/j.msea.2006.02.133

[3] JIRKOVÁ, H. et al.: Influence of metastable retained austenite on macro and micromechanical properties of steel processed by the Q-P process, Journal of Alloys and Compounds, available online, Journal of Alloys and Compounds, 615 (2014) pp. 163-S168

[4] QIAN, Z., LIHE Q., JUN T., JIANGYING M., FUCHENG Z. Inconsistent effects of mechanical stability of retained austenite on ductility and toughness of transformation-induced plasticity steels, Materials Science \& Engineering A, 2013, vol. 578, pp. 370-376.

[5] MONKA, P., HLOCH, S., ANDREJ, A., SOMSAK, M., MURGAS, F. Simulation Tools Used at the Injection Mould Design, Manufacturing Technology, Volume 16, 2016, Pages 561569

[6] CHOVANEC, A., BREZNICKÁ, A., Some Aspeckts of a Manufacturing process Simulation, Manufacruring Technology, Volume 17, 2017, Pages 319-325

[7] JENÍČEK, Š., VOREL, I., KÁŇA, J., OPATOVÁ, $\mathrm{K}$. The Use of Material-Technological Modelling to Determine the Effect of Temperature and Amount of Deformation on Microstructure Evolution in a Closed-Die Forging Treated by Controlled Cooling, Manufacturing Technology, Vol. 17, 2017, pp. 326-330

[8] http://www.sentesoftware.co.uk/

[9] GENG LIU A, JUN LI B, SHENGEN ZHANG, JIAN WANG B, QINGGE MENG. Dilatometric study on the recrystallization and austenization behavior of cold-rolled steel with different heating rates, Journal of Alloys and Compounds, (2016), Vol. 666, pp. 309-316

[10] Norma SEP1681, Juni 1998 